\title{
Alteration in brain glucose metabolism induced by hypoglycaemia in man
}

\section{P.J . B oyle}

Department of Medicine, Division of Endocrinology and Metabolism, University of New Mexico, Albuquerque, New Mexico, USA

Summary Glucose is the usual fuel of brain tissue. As hypoglycaemia develops, a level of glycaemia is reached where glucose transport from the circulation is no longer sufficient to meet metabolic demands, and the brain signals for peripheral counter-regulatory responses and symptoms of hypoglycaemia ensue. The glycaemic threshold for these events can be shifted to lower glucose concentrations following a single episode of hypoglycaemia, and compensating central nervous system adaptations have been postulated in man. In nondiabetic subjects, rates of brain glucose uptake are initially impaired at a systemic glucose concentration of $3.6 \mathrm{mmol} / \mathrm{l}$; whereas after $56 \mathrm{~h}$ of intermittent hypoglycaemia $(3.0 \mathrm{mmol} / \mathrm{l})$ brain uptake is preserved at normal rates even at $2.5 \mathrm{mmol} / 1$. Increments in counter-regulatory hormones and symptoms are also triggered at lower glucose concentrations following recurrent hypoglycae- mia. In 24 patients with insulin-dependent diabetes stratified into three equal groups by $\mathrm{HbA}_{1 \mathrm{c}}$ value, those in the lowest third of $\mathrm{HbA}_{1 \mathrm{c}}$ range had rates of brain glucose uptake at $3.0 \mathrm{mmol} / \mathrm{l}$ that were equivalent to rates measured at $5.3 \mathrm{mmol} / \mathrm{l}$. Patients in the other $\mathrm{HbA}_{1 \mathrm{c}}$ groups had rates of brain glucose uptake during hypoglycaemia that were reduced by $30 \%$ relative to normoglycaemia - comparable to reductions seen in non-diabetic subjects. Thus, alterations in glucose uptake occur in the brain in order to maintain normal brain metabolism following experimental and clinical hypoglycaemia. Because of this enhanced glucose uptake, the brain has no need to signal for counter-regulatory responses and hypoglycaemia unawareness occurs. [Diabetologia (1997) 40: S 69-S 74]

Keywords Brain metabolism, glucose metabolism, hypoglycaemia, counter-regulation, epinephrine.
Intensified diabetes management is associated with a threefold increased risk of severe hypoglycaemia (seizures, comas or requiring the assistance of another person to recover from hypoglycaemia) [1]. During the Diabetes Control and Complications Trial [1], over $50 \%$ of such episodes occurring while patients were awake happened with none of the usual warning symptoms of hypoglycaemia [1]. A proportional hazards risk model that included a variety of presumed risk factors associated with hypoglycaemia could explain only $7 \%$ of these severe episodes [1].

Corresponding author: P. J. Boyle, MD, UNM School of Medicine, Department of Medicine/Endo-5ACC, Albuquerque, N.M. 87131-5271, USA

A bbreviations: IDDM, Insulin-dependent diabetes mellitus.
Studies conducted during the mid 1980 s in insulin-dependent diabetic (IDDM) patients who had achieved near normoglycaemia established that a defect in epinephrine secretion accompanies intensified diabetes management [2]. Subsequent investigations confirmed this observation and proved that the epinephrine secretory defect was associated with a loss of awareness of hypoglycaemia [3]. The mechanism explaining why epinephrine responses become blunted following recurrent hypoglycaemia has not been thoroughly investigated and is the focus of this discussion.

The brain is an obligate glucose consumer and derives its fuel from the circulation through an insulinindependent process that begins with the transport of glucose from the circulation across the capillary endothelial surface via the GLUT 1 transport protein $[4,5]$. From the interstitium, it then completes its 


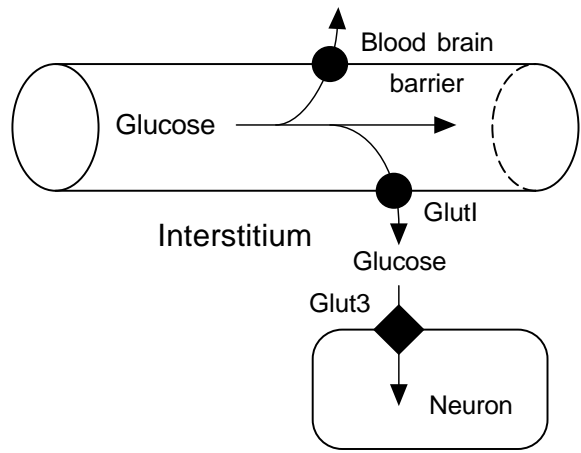

Fig. 1. Glucose transport from the cerebral arteriole to the neuron

uptake to either neuron or glial cells largely via the GLUT3 transporter (Fig.1). The regulation of the glucose transporter number on the capillary endothelial surface is believed to be regulated, in part, by the ambient systemic glucose concentration [6]. Under normal conditions, rates of brain glucose uptake are not rate-limiting for metabolism, in that roughly twice as much glucose is transported as is needed to satisfy brain energy needs [4]. That which is not utilized is available for transport back into the circulation since the brain has limited capacity to store glucose as glycogen [4]. At some critical systemic glucose concentration, glucose transport will become ratelimiting and hexokinase will not be saturated leading to reduced glucose 6-phosphate and impaired neural metabolism.

Novel experiments conducted by Biggers et al. [7] and Frizzell et al. [8] utilizing a canine model explored the role of the central nervous system in regulating the counter-regulatory hormone response. In these studies, vertebral and carotid arteries were infused with glucose at a rate designed to maintain brain normoglycaemia while systemic hypoglycaemia was generated. Compared to control animals which were allowed to experience the usual brain hypoglycaemia, the animals whose brains had normal glucose concentrations had substantially attenuated epinephrine and glucagon responses. In addition, the vagally mediated response for the release of pancreatic polypeptide during hypoglycaemia was also blunted suggesting that maintenance of head normoglycaemia satisfies a brain glucose sensing area's need for fuel and fails to initiate autonomic nervous system responses. As discussed by Jacobs et al. [9] the ventromedial hypothalamic nucleus appears to be the primary regulator of the counter-regulatory hormone response, sensing and signalling for increments in epinephrine. The bulk of symptoms of hypoglycaemia are identified as the result of increased sympathoadrenal tone, with the remainder occurring secondary to neuroglycopenia [10]. Based on available animal studies, Cryer [11] suggested that the ambient level of glycaemia might be a major factor leading to alterations in counter-regulation and be tied somehow to awareness of hypoglycaemia in man.

The mechanism by which ambient glucose levels lead to altered rates of brain glucose extraction were explored by Matthaei et al. [12]. These studies evaluated the possibility that chronic hyperglycaemia would lead to a 'down-regulation' of glucose transport capacity on capillary endothelial cells in the brain. Diminished concanavalin-B binding, an indirect marker of glucose transporter number, was documented in brain homogenates of chronically hyperglycaemic animals. These early findings were later confirmed by decreased brain glucose extraction [13] in the setting of poorly controlled diabetes in rodents. We have previously demonstrated that patients in poor metabolic control experience symptoms of hypoglycaemia at higher glucose concentrations than nondiabetic individuals - consistent with the notion that fewer transporters are produced in response to hyperglycaemia, and such patients would be predisposed to develop symptoms at relatively normal glucose concentrations [13]. Conversely, in the setting of chronic hypoglycaemia, glucose extraction is upregulated in rodents [14] and glucose transporter number increased in isolated capillary endothelial cells deprived of glucose $[6,15,16]$. While the precise molecular biology leading to this later adaptation remains to be elucidated, it is associated with increased mRNA content for the GLUT1 transporter protein in brain capillary endothelial cells [17]. Enhanced glucose uptake at the blood brain barrier leads to maintenance of normal energy metabolism with chronic hypoglycaemia. This normalization of brain energy state is best demonstrated in animals implanted with insulinoma who have brain ATP and glucose 6-phosphate levels within the normal range despite dramatically low glucose concentrations [15].

Human investigations that complement these findings are limited. Gutniak et al. [18], utilizing ${ }^{11} \mathrm{C}$-glucose and positron emission tomography, found no differences in rates of brain glucose metabolism at hypoglycaemia in IDDM patients in good metabolic control compared to nondiabetic subjects. The basal rates of brain glucose metabolism during normoglycaemia were approximately half those normally observed, therefore placing the findings in question. Direct measurement of brain glucose uptake is made in our laboratory by multiplying cerebral blood flow by the cross brain arteriovenous glucose concentration. This technique requires retrograde cannulation of the internal jugular bulb to permit sampling of cerebrocortical venous drainage. Carotid arterial glucose concentration is approximated by radial arterial sampling. Fick methodology is applied to measure cerebral blood flow by having subjects inhale a low concentration of an inert tracer gas, in our case, nitrous oxide $[19,20]$. When the integrated area between the arterial and venous nitrous oxide curves is divided 
into the venous equilibrium concentration of the gas, cerebral blood flow is yielded. Using this methodology, we wished to establish that the mechanism for the development of hypoglycaemia unawareness was through enhanced brain glucose uptake. Because we presumed that enhanced uptake would be the result of increased transport capacity, a period of $56 \mathrm{~h}$ of episodic hypoglycaemia was selected for the first of our investigations in order to parallel the in vitro experiments of Takahura et al. [16] who showed a $60 \%$ increase in protein in isolated brain capillary endothelial cells deprived of glucose.

A baseline day of study was conducted in 12 nondiabetic subjects who had retrograde internal jugular and radial arterial cannulas placed prior to lowering the glucose concentrations in a step-wise fashion from 4.7 to $2.5 \mathrm{mmol} / \mathrm{l}$ in approximately $1 \mathrm{~h}$ long steps [20]. Brain glucose uptake was maintained at normal rates at 4.7 and $4.2 \mathrm{mmol} / \mathrm{l}$; but fell significantly at $3.6 \mathrm{mmol} / \mathrm{l}$. This initial impairment in brain uptake co-ordinates with the known first decrease in brain glucose 6-phosphate concentrations in rodents observed by Lewis et al. [21]. Further decrements in systemic glucose concentrations caused lowering in brain glucose uptake (Fig.2). Epinephrine secretion began at $4.2 \mathrm{mmol} / \mathrm{l}$, thus actually occurring at higher plasma glucose concentrations than that required to change whole brain glucose uptake. Next in the sequence of events, autonomic symptoms began at $3.6 \mathrm{mmol} / 1$ followed by neuroglycopenic symptoms at $3.1 \mathrm{mmol} / \mathrm{l}$. The explanation for the difference in the level of glycaemia required to initiate epinephrine secretion compared to that required to impair brain glucose uptake may lie in the accuracy of our measurement which has an ability to detect approximately a $10 \%$ change between glycaemic steps with this number of patients. Another possible explanation is that regional differences exist for the impairment in glucose uptake and the glucose sensing centres in the hypothalamus may experience reduced glucose uptake at higher glucose concentrations than that required for whole brain. Unfortunately, the cross brain glucose uptake methodology we employ cannot identify regional differences.

Following this preliminary day of study, subjects' arterial glucose concentrations were maintained at approximately $3.0 \mathrm{mmol} / \mathrm{l}$ for $56 \mathrm{~h}$, returning toward normal only during postprandial periods. On the final day, the arterial glucose concentration was raised to $4.2 \mathrm{mmol} / 1$ and then reduced in a step-wise fashion equivalent to the first day of study. After recurrent hypoglycaemia, no significant reduction in brain glucose uptake was observed even at $2.5 \mathrm{mmol} / \mathrm{l}$ and rates were comparable to those observed at $4.7 \mathrm{mmol} / \mathrm{l}$ on the first day of the study. Likewise, symptoms of hypoglycaemia and epinephrine concentrations rose at significantly lower glucose concentrations on the final day. In summary of this study,
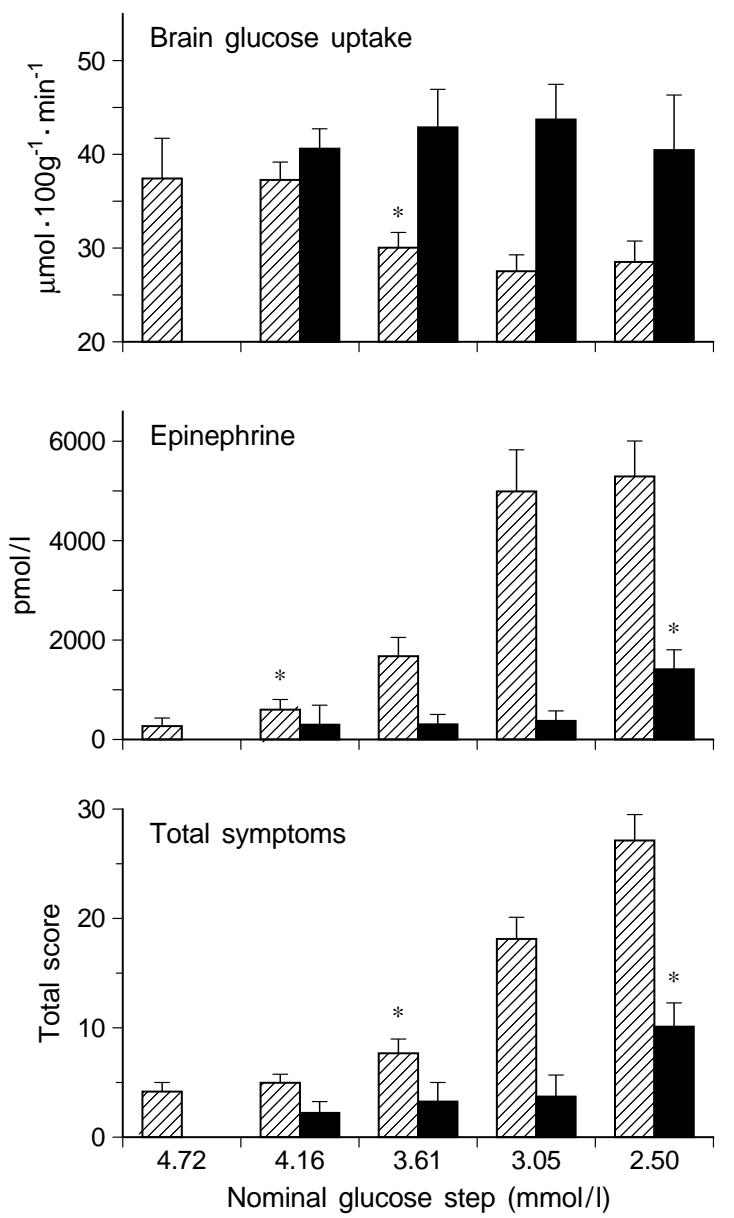

Fig. 2. Rates of brain glucose uptake, epinephrine concentration, and total symptoms of hypoglycaemia in normal subjects before and after recurrent hypoglycaemia. Initial day of investigation $\mathbb{Z}$; after $56 \mathrm{~h}$ recurrent hypoglycaemia $\square$. P-values are from repeated measure ANOVA tests between the 2 study days, * first significant difference from baseline for each of the 2 days by two-tailed Student's t-test. Reproduced with permission from Proc Nat Acad Science USA

under normal conditions, transport becomes rate limiting for whole brain glucose uptake at approximately $3.6 \mathrm{mmol} / \mathrm{l}$. Because our methodology does not measure regional changes, we cannot exclude that finite initial impairment in critical glucose sensing regions of the hypothalamus may have occurred. The major finding that the central nervous system can adjust its acquisition of fuel following periods of recurrent glucose deficiency suggested that patients with diabetes might similarly undergo metabolic adaptations in brain glucose transport in response to clinical hypoglycaemia.

In the second investigation to be described in detail, 24 patients with IDDM were studied and their responses to hypoglycaemia compared to those of non-diabetic subjects [22]. The experimental protocol for these patients called for the plasma glucose concentration to be reduced from $5.3 \mathrm{mmol} / \mathrm{l}$ to $3.0 \mathrm{mmol} / \mathrm{l}$ with brain glucose uptake determined at 


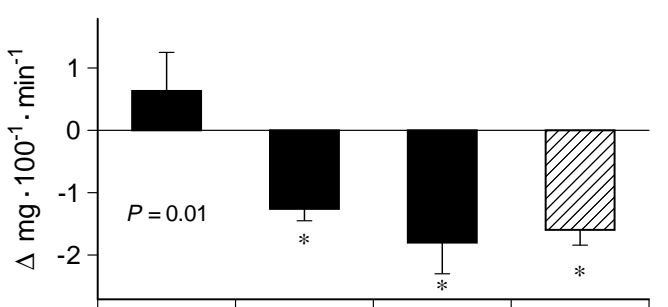

a

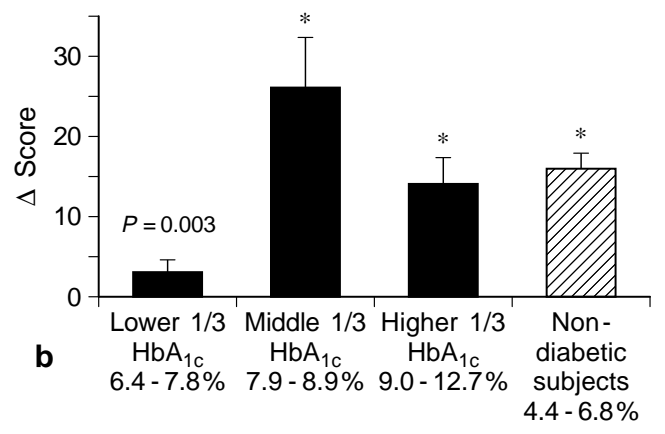

Fig. 3a-d. Change in rate of brain glucose uptake (a), symptoms of hypoglycaemia (b), epinephrine (c) and pancreatic polypeptide (d) responses as glucose is decreased from 5.5 to $2.5 \mathrm{mmol} / \mathrm{l}$ in 24 IDDM patients and 13 normal subjects. $P$-values represent results of ANOVA testing among groups with diabetes (stratified into three equal groups by haemoglobin $A_{1 c}$ value).* Significant difference from lowest third haemoglobin $\mathrm{A}_{1 \mathrm{c}}$ group

both levels. The data for the patients were then stratified into three equal haemoglobin $\mathrm{HbA}_{1 \mathrm{c}}$ groups and are presented as changes in rate relative to normoglycaemia along with epinephrine and pancreatic polypeptide responses (Fig. 3). The patients were similar in age and duration of diabetes, and had no longterm diabetic complications. They were treated with a variety of insulin regimens including Ultralente and Regular insulins. Only one patient in the lower $\mathrm{HbA}_{1 \mathrm{c}}$ group was using a subcutaneous insulin infusion pump. During hypoglycaemia, the patients in the middle and higher thirds of the $\mathrm{HbA}_{1 \mathrm{c}}$ distribution had reductions in brain glucose uptake that were comparable to those observed in the non-diabetic subjects (approximately a 30\% overall fall from normoglycemic rates). Conversely, those patients in the lowest $\mathrm{HbA}_{1 \mathrm{c}}$ group had no significant change in brain glucose uptake during hypoglycaemia ( $p<0.03$ among $\mathrm{HbA}_{1 \mathrm{c}}$ groups). Symptoms, epinephrine and pancreatic polypeptide responses were similarly blunted in the lowest $\mathrm{HbA}_{1 \mathrm{c}}$ group.

One major controversy clearly remains to be resolved in association with recurrent hypoglycaemia and changes in neural metabolism. One should expect that if whole brain glucose uptake is preserved to lower systemic glucose concentrations, then certain aspects of cognitive function might also be preserved during hypoglycaemia. A limited battery of
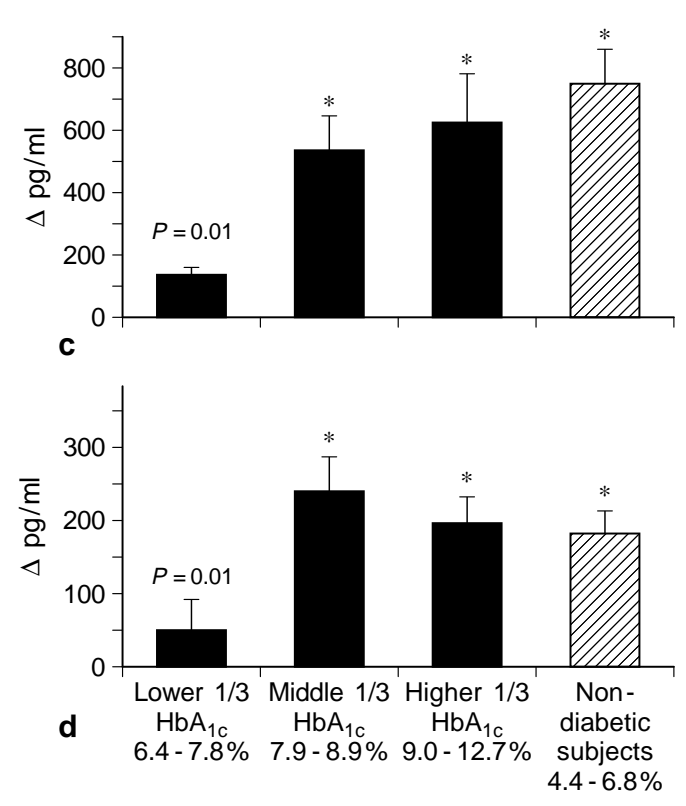

tests was used to assess cognitive function during both of the investigations described above. Motor function, as assessed by finger tapping, was impaired at $3.1 \mathrm{mmol} / \mathrm{l}$ on the initial day of study, but was not impaired even at $2.5 \mathrm{mmol} / \mathrm{l}$ after the $56 \mathrm{~h}$ period of recurrent hypoglycaemia in the non-diabetic subjects. We also employed the Stroop test, the performance of which has been shown by positron emission tomography studies to require activation and inhibition of multiple cerebrocortical areas [23]. This index of cortical function was impaired at $3.0 \mathrm{mmol} / \mathrm{l}$ on the baseline day of study but not until $2.5 \mathrm{mmol} / \mathrm{l}$ after the period of recurrent hypoglycaemia in the nondiabetic study. The Stroop test is traditionally viewed as an attentional task and, thus the improved results we have seen may in part be related to improved attention. Still, attention is required to perform any cognitive task and may contribute to many investigators' anecdotal perception that cognitive performance is preserved during hypoglycaemia in intensively treated patients. A variety of tests of neural function including EEG and auditory evoked potential have failed to document changes in glycaemic threshold required to alter brain electrical activity in patients with wellcontrolled IDDM [24, 25]. On the other hand, direct measurement of auditory evoked potentials at the superior colliculus in the brain stem suggests that electrical transport is improved following chronic hypoglycaemia [8].

The mechanisms which may contribute to this adaptation in man deserve discussion. Based on animal models of hypoglycaemia, GLUT1 transporter number is likely to increase, but increased transporter density per unit of surface area is not the only possible way to enhance glucose uptake. The uptake of glucose is also dependent on flow and total capillary surface areas available to permit transport [26]. Cerebral blood flow increased by approximately $30 \%$ in 
the non-diabetic subject studies which might be expected to facilitate transport substantially, but due to the exponential nature of transport kinetics through membranes [27], a doubling in linear flow through brain capillaries only increases brain glucose uptake by about $8 \%$ [20]. On the other hand, if the available capillary volume (and thus transport surface area) were to increase slightly, then a modest increase in flow would occur, but transport would increase dramatically [20]. Prior studies by Skov and Pyrds [28] have suggested that in human infants, an increase in cerebrovascular volume can occur during hypoglycaemia.

The adaptation induced by hypoglycaemia is undoubtedly reversible. IDDM patients, intensively managed to minimize hypoglycaemia, can revert their glycaemic threshold for initiating symptoms and counter-regulatory hormone release to higher glucose concentrations [29-31]. Even patients with overall poor glycaemic control (as judged by $\mathrm{HbA}_{1 \mathrm{c}}$ ) can develop hypoglycaemia unawareness and defective counter-regulation if they experience episodic hypoglycaemia prior to study [32]. One natural experiment has contributed to our understanding on this issue of reversibility. Patients with insulinoma studied to determine glycaemic thresholds for counter-regulatory hormone secretion, impairment in cognitive function and ability to identify hypoglycaemic symptoms required higher glucose concentrations to initiate each of these parameters after restoration of normoglycaemia by tumour removal than while they were chronically hypoglycaemic [32].

In conclusion, hypoglycaemia unawareness is the result of enhanced brain glucose uptake in patients with IDDM. The frequency and absolute duration of hypoglycaemia required to induce these changes in brain metabolism is not explained by either of our studies. Due to the invasive nature of replacing internal jugular and radial arterial cannulas, we did not attempt to map out the time course of this mechanism. The eight patients in the lower $\mathrm{HbA}_{1 \mathrm{c}}$ group experienced measured glucose concentrations less than $3.5 \mathrm{mmol} / \mathrm{l}$ a mean of seven times during the week prior to the investigation, significantly more than in those patients in the other groups $(p=0.003)$. A single episode of hypoglycaemia can begin to blunt sympathoadrenal responses to hypoglycaemia [33], but whether or not this is a result of altered whole brain metabolism or other mechanisms is not known. Treatment strategies that produce near normoglycaemia with the minimum of hypoglycaemia should be the patient's and physician's goal. The enhancement in brain glucose uptake that is induced following recurrent hypoglycaemia may be viewed as a useful adaptation given that it permits patients to maintain normal brain metabolism, including some aspects of cognitive ability during the subsequent hypoglycaemia. From the stand point of patient safety, however, by the time that the systemic glucose concentration reaches a critical threshold to initiate symptoms of hypoglycaemia, the patient may not be able to react quickly enough to avert severe neuroglycopenia and loss of consciousness. Therefore, enhanced brain glucose uptake in patients with well-controlled IDDM may be considered maladaptive.

A cknowledgements. This research was supported by NIH FIRST Award 1 R29 NS29972-01A1. These projects were supported in part by dedicated Health Research Funds of the University of New Mexico and by a grant from General Clinical Research Program, DRR, NIH 5 M01 RR00997-19,20.

\section{References}

1. The DCCT Research Group (1991) Epidemiology of severe hypoglycaemia in the Diabetes Control and Complications Trial. Am J Med 90: 450-459

2. Simonson DC, Tamborlane WV, DeFronzo RA, Sherwin RS (1985) Intensive insulin therapy reduces counterregulatory hormone responses to hypoglycaemia in patients with type 1 diabetes. Ann Intern Med 103: 184-190

3. Amiel SA, Sherwin RS, Simonson DC, Tamborlane WV (1988) Effect of intensive insulin therapy on glycemic thresholds for counterregulatory hormone release. Diabetes 37: 901-907

4. Pardridge WM (1983) Brain metabolism: a perspective from the blood-brain barrier. Physiol Rev 63(4):1481-1535

5. Pardridge WM, Boado RJ, Farrell CR (1990) Brain-type glucose transporter (GLUT-1) is selectively localized to the blood-brain barrier: Studies with quantitative western blotting and in situ hybridization. J Biol Chem 265: 1803518040

6. Koryanyi L, Bourey RE, James D, Mueckler M, Fiedorek FT Jr, Permutt MA (1991) Glucose transporter gene expression in rat brain: pretranslational changes associated with chronic insulin-induced hypoglycaemia, fasting and diabetes. Mol Cell Neurosci 2: 244-252

7. Biggers DW, Myers SR, Stinson ND et al. (1989) Role of brain in counterregulation of insulin-induced hypoglycaemia in dogs. Diabetes 38: 7-16

8. Frizzell RT, Jones EM, Davis SN (1993) Counterregulation during hypoglycaemia is directed by widespread brain regions. Diabetes 42: 1253-1261

9. Jacobs RJ, Weber AB, Dziura J, Morgen J, Sherwin RS (1996) Brain stem dysfunction is provoked by a less prounounced hypoglycemic stimulus in diabetic BB rats. Diabetes 44: 900-905

10. Towler DA, Havlin CE, Suzanne C, Cryer PE (1993) Mechanism of awareness of hypoglycaemia: perception of neurogenic (predominantly cholinergic) rather than neuroglycopenic symptoms. Diabetes 42: 91-98

11. Cryer PE (1985) Does central nervous system adaptation to antecedent glycaemia occur in patients with insulin-dependent diabetes mellitus? Ann Intern Med 103: 284-286

12. Matthaei S, Horuk R, Olefsky JM (1986) Blood-brain glucose transfer in diabetes mellitus: decreased number of glucose transporters at blood-brain barrier. Diabetes 35: 11811184

13. Boyle PJ, Schwartz NS, Shah SD, Clutter WE, Cryer PE (1988) Plasma glucose concentrations at the onset of hypoglycemic symptoms in patients with poorly controlled diabetes and in nondiabetics. N Engl J Med 318: 1487-1492 
14. McCall AL Millington WR, Wurtman RJ (1982) Metabolic fuel and amino acid transport into the brain in experimental diabetes mellitus. Proc Natl Acad Sci USA 79: 54065410

15. McCall AL, Fixman LB, Fleming N, Tornheim K, Chick W, Ruderman NB (1986) Chronic hypoglycaemia increases brain glucose transport. Am J Physiol 251:E442-E447

16. Takakura Y, Kuentzel SL, Raub TJ, Davies A, Baldwin SA, Borchardt RT (1991) Hexose uptake in primary cultures of bovine microvessel endothelial cells. I. Basic characteristics and effects of D-glucose and insulin. Biochim Biophys Acta 1070: $1-10$

17. Boado RJ, Pardridge WM (1993) Glucose deprivation causes post-translational enhancement of brain capillary endothelial glucose transporter gene expression via GLUT1 mRNA stabilization. J Neurochem 60: 2290-2296

18. Gutniak M, Blomqvist G, Widén L, Stone-Elander S, Hamberger B, Grill V (1990) D-[U- $\left.{ }^{11} \mathrm{C}\right]$ glucose uptake and metabolism in the brain of insulin-dependent diabetic subjects. Am J Physiol 258 [Endocrinol Metab 21]:E805-E812

19. Boyle PJ, Scott JC, Krentz AJ, Nagy RJ Comstock E, Hoffman C (1994) Diminished brain glucose metabolism is a significant determinant for falling rates of systemic glucose utilization during sleep in normal humans. J Clin Invest 93: 529-535

20. Boyle PJ, Nagy RJ, O'Connor AM, Kempers SF, Yeo RA, Qualls C (1994) Adaptation in brain glucose uptake following recurrent hypoglycaemia. Proc Natl Acad Sci USA 91: 9352-9356

21. Lewis LD, Ljunggren B, Norberg K, Siesjö BK (1974) Changes in carbohydrate substrates, aminoacids and ammonia in the brain during insulin-induced hypoglycaemia. J Neurochem 23: 659-671

22. Boyle PJ, Kempers SK, O'Connor AM, Nagy RJ (1995) Brain glucose uptake and hypoglycaemia unawareness in patients with insulin dependent diabetes mellitus.N Engl J Med 333: 1726-1731
23. Bench CJ, Frith CD, Grasby PM et al. (1993) Investigations of the functional anatomy of attention using the Stroop test. Neuropsychologia 31: 907-922

24. Amiel SA, Pottinger RC, Archibald HR, Chusney G, Cunnah DT, Prior PF, Gaze EA. Diabetes Care 14: 109118

25. Jones TW, McCarthy G, Tamborlane WV et al. (1990) Mild hypoglycaemia and impariment of brain stem and cortical evoked potential in healthy subjects. Diabetes 39: 1550 1555

26. Pelligrino DA, Lipa MD, Albrecht RF (1990) Brain glucose utilization and transport and cortical function in chronic vs acute hypoglycaemia. Am J Physiol 259:E729-E735

27. Gjedde A, Chrone C (1981) Blood-brain glucose transfer: repression in chronic hyperglycaemia. Science 214: 456-457

28. Skov L, Pyrds O (1992) Capillary recruitment for preservation of cerebral glucose influx in hypoglycemic, preterm newborns: evidence for a glucose sensor? Pediatrics 90: 193-195

29. Fanelli CG, Epifano L, Rambotti AM, et al. (1993) Meticulous prevention of hypoglycaemia normalizes the glycemic thresholds and magnitude of most of neuroendocrine responses to symptoms of hypoglycaemia in intensively treated patients with short-term IDDM. Diabetes 42: 1683-1689

30. Cranston I, Lomas J, Maran A, Macdonald I, Amiel SA (1994) Restoration of hypoglycaemia awareness in patients with long-duration insulin-dependent diabetes. Lancet 344 : 283-287

31. Dagogo-Jack S, Rattarasarn C, Cryer PE (1994) Reversal of hypoglycaemia unawareness, but not defective glucose counterregulation in IDDM. Diabetes 43: 1426-1434

32. Mitrakou A, Fanelli C, Veneman T, et al. (1993) Reversibility of unawareness of hypoglycaemia in patients with insulinomas. N Engl J Med 329: 834-839

33.Heller SR, Cryer PE (1991) Reduced neuroendocrine and symptomatic responses to subsequent hypoglycaemia after 1 episode of hypoglycaemia in nondiabetic humans. Diabetes 40: 223-226 